\title{
Cigarette Smoking Among Urban American Indian Adults - Hennepin and Ramsey Counties, Minnesota, 2011
}

\author{
Jean Forster, $\mathrm{PhD}^{1}$; John Poupart, $\mathrm{MPA}^{2}$; Kristine Rhodes, $\mathrm{MPH}^{3}$; Melanie Peterson-Hickey, $\mathrm{PhD}^{4}$; Genelle Lamont, $\mathrm{MPH}^{5}$;
} Joanne D'Silva, $\mathrm{MPH}^{6}$; Darin Erickson, $\mathrm{PhD}^{1}$

In 2013, it was estimated that the prevalence of cigarette smoking among American Indians was 36.5\%, the highest of all racial/ethnic groups in the continental United States (1). Among American Indians, considerable cultural and geographic variation in cigarette smoking exists. Smoking prevalence among American Indians is lowest in the Southwest and highest in the Upper Midwest/Northern Plains (2). Little information is available about tobacco use among urban American Indians, who might not have ever lived on a reservation or be enrolled in or affiliated with a tribe. In Minnesota, a significant proportion of American Indians reside in urban areas. Among Minnesota's residents who identify as American Indian alone or in combination with another race, 30\% live in Hennepin County and Ramsey County, which encompass Minneapolis and St. Paul, respectively (collectively known as the Twin Cities). The predominant tribes (Ojibwe [Chippewa] and Dakota/Lakota/Nakota [Sioux]) traditionally have used locally grown tobacco (Nicotiana rustica), red willow, and other plants for religious ceremonies, although nonceremonial tobacco is often substituted for traditional plants. To assess prevalence of cigarette smoking among this population, it is important to distinguish ceremonial tobacco use (smoked or used in other ways) from nonceremonial tobacco use. To obtain estimates of cigarette smoking prevalence among American Indians in Hennepin and Ramsey counties, the American Indian Adult Tobacco Survey was administered to 964 American Indian residents in 2011, using respondent-driven sampling. Among all participants, 59\% were current smokers, $19 \%$ were former smokers, and 22\% had never smoked. Approximately $40 \%$ of employed participants reported that someone smoked in their workplace area during the preceding week. High prevalences of cigarette smoking and secondhand smoke exposure among urban American Indians in Minnesota underscores the need for a comprehensive and culturally appropriate approach to reducing nonceremonial tobacco use.

Because no lists of eligible respondents existed, the study sample was generated using respondent-driven sampling (3). Using this sampling scheme, identified respondents referred persons they knew, who in turn referred persons they knew. A mathematical model weighted the sample to compensate for the fact that it was collected in a nonrandom way. Each participant, beginning with the initial five respondents (called seeds) chosen by investigators, was given three coupons with unique identification numbers to give to other eligible participants. This process continued through 12 rounds of recruitment to produce a sufficient sample for prevalence estimates with a reasonable margin of error. Eligible participants were aged $\geq 18$ years, self-identified as American Indian (alone or in combination with other races), and resided in Hennepin or Ramsey counties. Only one respondent per household was eligible. Data were collected in community settings through face-to-face interviews by American Indian interviewers who received training in interviewing and human subject protection. Participants received a $\$ 15$ gift card for participating in the survey and a $\$ 10$ gift card for each of their participating coupon recipients. This study was approved by the University of Minnesota Institutional Review Board (IRB), the Fond du Lac Reservation IRB, and the Indian Health Service IRB.

The survey was conducted during March-May, 2011, and was based on the American Indian Adult Tobacco Survey (4). It included questions about spiritual, ceremonial, nonceremonial, and smokeless tobacco use, including information on initiation and quitting; secondhand smoke exposure; attitudes and knowledge about nonceremonial tobacco, including harms and social acceptability; and participant demographics, including age, sex, education level, and household income. To determine cigarettesmoking status, participants were asked the following question: "Not including ceremonial or sacred use....in your entire life have you smoked at least 100 cigarettes?" Respondents who answered "yes" were asked, "Do you usually now smoke cigarettes every day, some days, or not at all?" Current smokers were defined as participants who had ever smoked at least 100 cigarettes and at the time of the survey smoked every day or some days. Former smokers were defined as persons who had smoked at least 100 cigarettes and at the time of the survey did not smoke at all, and never smokers were defined as participants who had not smoked 100 cigarettes in their lifetimes. Smokers were asked about willingness to use various smoking cessation aids or methods, including nicotine replacement therapy, buproprion or varenicline products, various quit smoking modalities, and traditional tribal practices. Participants were asked if, during the previous week, anyone had smoked tobacco around them in their house, in a car, where they work, or somewhere else, other than for ceremonial or sacred purposes. Raw data were adjusted for network size using weights generated by the RDS Analysis Tool.* Data were further weighted by gender, age, and county of residence distribution

\footnotetext{
${ }^{*}$ RDS $=$ respondent-driven sampling. RDS Analysis Tool v5.6 user manual (http://www.respondentdrivensampling.org/reports/RDSAT_56_Manual.pdf).
} 
of American Indians (alone or in combination with other races) from the U.S. Census. Data were compared with data from the 2010 Minnesota Adult Tobacco Survey (5).

The target sample size was 1,000 participants, based on estimates of detectable differences in smoking rates by demographic categories. The survey was administered to 964 persons, and yielded 940 usable responses. The unweighted sample closely matched the age distribution for American Indians from the 2010 U.S. Census, but women and Hennepin County residents were overrepresented. Most respondents (87\%) were enrolled ${ }^{\dagger}$ in a tribe $(65 \%$ Ojibwe, $20 \%$ Dakota/Lakota, $2 \%$ other $)$. Sixty-four percent of participants were female; $18 \%$ were aged $18-24$ years, $45 \%$ were aged $25-44$ years, $32 \%$ were aged $45-64$ years, and $5 \%$ were aged $\geq 65$ years.

The estimated prevalences of current smoking, former smoking, and never smoking in this population were $59.3 \%, 18.5 \%$, and $22.1 \%$, respectively (Table 1 ). The estimated current smoking prevalence among women $(55.8 \%)$ was lower than among men (63.7\%); estimated prevalence of current smoking was highest among persons aged 25-44 years (72.4\%) and lowest among persons aged $\geq 65$ years $(28.8 \%)$. The estimated prevalence of never having smoked was highest among persons aged 18-24 years (41.6\%). No association of smoking status with educational level was evident. The largest percentage of smokers in this sample (39.4\%) smoked $\leq 5$ cigarettes on days they smoked, but $70.5 \%$ reported that they had smoked at least

\footnotetext{
${ }^{\dagger}$ Membership in a tribe based on tribally determined criteria, such as ancestry and tribal blood quantum.
}

TABLE 1. Estimates of smoking status* of American Indians aged $\geq 18$ years - Hennepin and Ramsey Counties, Minnesota, 2011

\begin{tabular}{|c|c|c|c|}
\hline Characteristic & $\begin{array}{c}\text { Current } \\
\text { smokers }^{\dagger} \\
\%(95 \% \mathrm{Cl})\end{array}$ & $\begin{array}{c}\text { Former } \\
\text { smokers } \\
\%(95 \% \mathrm{Cl})\end{array}$ & $\begin{array}{c}\text { Never } \\
\text { smokers? } \\
\%(95 \% \mathrm{Cl})\end{array}$ \\
\hline Overall & $59.3(56.7-61.9)$ & $18.5(16.5-20.5)$ & $22.1(19.9-24.3)$ \\
\hline $\begin{array}{l}\text { Gender } \\
\text { Men } \\
\text { Women }\end{array}$ & $\begin{array}{l}63.7(59.4-68.0) \\
55.8(52.6-59.0)\end{array}$ & $\begin{array}{l}17.2(13.9-20.5) \\
19.6(17.1-22.1)\end{array}$ & $\begin{array}{l}19.2(15.8-22.6) \\
24.6(21.8-27.4)\end{array}$ \\
\hline $\begin{array}{l}\text { Age group (yrs) } \\
18-24 \\
25-44 \\
45-64 \\
\geq 65\end{array}$ & $\begin{array}{l}52.0(46.4-57.6) \\
72.4(68.4-76.4) \\
51.5(47.4-55.6) \\
28.8(20.7-36.9)\end{array}$ & $\begin{array}{r}6.4(3.9-8.9) \\
12.8(9.6-16.0) \\
28.9(25.1-32.7) \\
48.1(39.1-57.1)\end{array}$ & $\begin{array}{l}41.6(35.9-47.3) \\
14.6(11.9-17.7) \\
19.6(16.1-23.1) \\
23.1(15.3-30.9)\end{array}$ \\
\hline $\begin{array}{l}\text { Education } \\
\text { No high school diploma } \\
\text { High school diploma } \\
\text { or GED } \\
\text { Postsecondary }\end{array}$ & $\begin{array}{l}56.3(51.0-61.6) \\
65.3(61.3-69.3)\end{array}$ & $\begin{array}{l}19.0(14.4-23.6) \\
16.1(13.4-18.8)\end{array}$ & $\begin{array}{l}24.7(20.6-28.8) \\
18.6(15.3-21.9)\end{array}$ \\
\hline
\end{tabular}

Abbreviations: $\mathrm{Cl}=$ confidence interval; $\mathrm{GED}=$ General Educational Development.

* Based on weighted sample of 940 residents of Hennepin and Ramsey Counties aged $\geq 18$ years.

† Smoked $\geq 100$ cigarettes in lifetime; currently smokes every day or some days.

$\S$ Smoked $\geq 100$ cigarettes in lifetime; currently does not smoke at all.

๑ Never smoked 100 cigarettes in lifetime.
20 days during the previous month. Regular filtered cigarettes (48.3\%) and menthol cigarettes (42.1\%) were predominantly reported to be the type of cigarette usually smoked (Table 2). Among persons who had ever smoked, 23.8\% reported that they had quit smoking. Two thirds (67.6\%) of current smokers indicated that they wanted to quit, and approximately half $(57.2 \%)$ had tried quitting during the previous year. When asked about willingness to use various smoking cessation aids or methods, a large proportion (42.9\%) said they would use nicotine replacement therapies. However, other medications like varenicline (a prescription nicotine agonist) or buproprion (a prescription antidepressant medication used as a smoking cessation aid) were less acceptable (16.6\%). A relatively small percentage (14.7\%) of current smokers were open to telephone support such as quit lines; individual or group support for cessation was more acceptable (36.9\% and $25.4 \%$ respectively). One third of participants (33.4\%) knew of a stop-smoking program, most often located in a local American Indian health clinic.

Survey participants reported a higher prevalence of secondhand smoke exposure in homes (41.5\%), cars (64.3\%), workplaces $(40.8 \%)$, and other places $(69.8 \%)$ than did residents of Minnesota as a whole in the 2010 Minnesota Adult Tobacco Survey (Figure) (5). Most (97\%) employed respondents reported working in a location other than a reservation.

\section{Discussion}

The prevalence of cigarette smoking among American Indians aged $\geq 18$ years in the urban area of the Twin Cities was $59 \%$, approximately four times greater than that of the overall Minnesota population estimate of $16 \%$ (5). Few comparable estimates of cigarette smoking among American Indians in the Twin Cities are available. Previous analyses reported a cigarette smoking prevalence of $36.6 \%$ for American Indians in Hennepin and Ramsey counties based on Behavioral Risk Factor Surveillance System data during 2005-2010 (G). A 2007 study based on a convenience sample of 300 American Indians in Minneapolis reported a smoking prevalence of 62\% (7). Precision and validity of Behavioral Risk Factor Surveillance System-based data and other surveillance estimates are limited by small sample size, culturally inappropriate data collection methods (e.g., use of telephone instead of face-toface interviews), lack of attention to ceremonial tobacco use, and exclusion of American Indians who indicate more than one race. This study was able to produce estimates of cigarette smoking prevalence among Twin Cities American Indians by using culturally appropriate methods.

Although smoking prevalence in the general population follows a strong education gradient (8) this gradient was not observed in this population. The cigarette smoking prevalence among persons aged $25-44$ years $(72 \%)$ is particularly 
TABLE 2. Estimated smoking patterns of current smokers* among American Indians aged $\geq 18$ years - Hennepin and Ramsey Counties, Minnesota, $2011^{\dagger}$

\begin{tabular}{lr}
\hline Characteristic & \multicolumn{1}{c}{$\begin{array}{c}\text { Smokers } \\
\%(95 \% \mathrm{Cl})\end{array}$} \\
\hline No. days smoked, past 30 days & \\
$1-5$ & $6.6(5.2-8.0)$ \\
$6-10$ & $11.2(7.9-14.5)$ \\
$11-19$ & $10.4(8.0-12.8)$ \\
$\geq 20$ & $70.5(66.8-74.2)$ \\
No. cigarettes smoked on days smoked & \\
$\leq 5$ & $39.4(35.8-43.0)$ \\
$6-10$ & $28.6(25.5-31.7)$ \\
$11-20$ & $25.9(22.8-29.0)$ \\
$\geq 21$ & $5.5(4.3-6.7)$ \\
Usual type of cigarettes & \\
Regular filtered & $48.3(44.7-51.9)$ \\
Menthol & $42.1(38.5-45.7)$ \\
Light/Ultra-light & $6.9(5.5-8.3)$ \\
Regular unfiltered & $1.6(0.9-2.3)$ \\
Natural (no additives) & $1.0(0.5-1.5)$ \\
\hline
\end{tabular}

Abbreviation: $\mathrm{Cl}=$ confidence interval.

* Have smoked $\geq 100$ cigarettes in lifetime; currently smokes every day or some days.

† Based on weighted sample of 940 residents of Hennepin and Ramsey Counties aged $\geq 18$ years.

concerning in light of the effect of adult smoking on youth behavior and on secondhand smoke exposure of youth (8). Participants reported much higher prevalences of secondhand smoke exposure, including at their workplace and at other places than did the general Minnesota population (5). The Minnesota state law that prohibits smoking in all indoor workplaces, restaurants, and bars does not apply on reservations; however, almost all of the employed respondents reported working in a non-reservation location, so most of the reported worksite secondhand smoke exposure represents potential noncompliance with Minnesota law. Most smokers have made quit attempts, but few have been successful. Food and Drug Administration-approved medications for smoking cessation and quit lines (the universally available method) were less well accepted among the participants than the other methods surveyed.

The findings in this report are subject to at least three limitations. First, data were self-reported, and neither smoking status nor secondhand smoke exposure were verified biochemically. However, self-reported smoking status has been shown to correlate highly with serum cotinine levels (9). Second, the unweighted sample overrepresents women and Hennepin County residents. For that reason, the data were weighted to the population distribution in the represented counties. Finally, response bias could have been introduced by respondent-driven sampling methods. However, the sampling and weighting procedures followed as part of
FIGURE. Percentage of persons who reported secondhand smoke exposure during the previous week, among urban* American Indians, 2011, and overall Minnesota, $2010^{\dagger}$

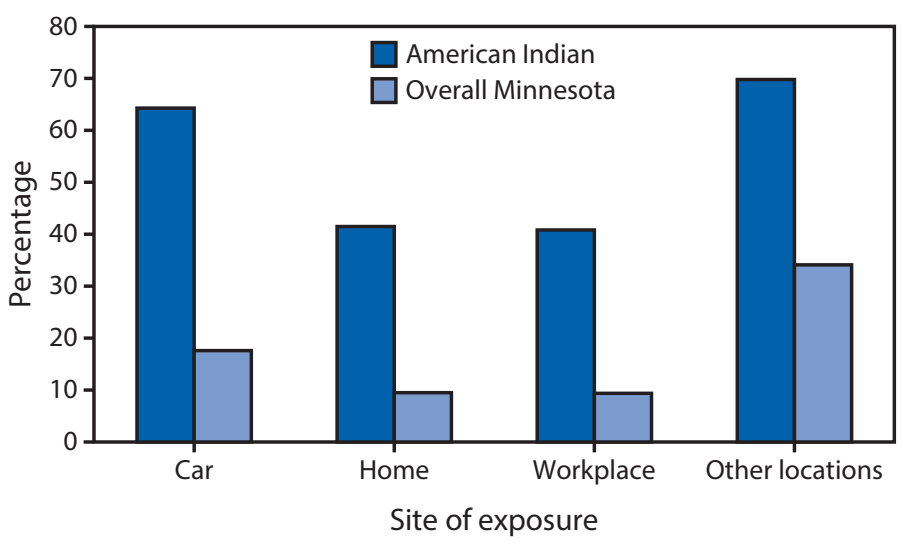

* Residing in Hennepin and Ramsey Counties, Minnesota.

† Overall data reported from 2010 Minnesota Adult Tobacco Survey.

respondent-driven sampling methods have been found to produce asymptotically unbiased estimates (3).

Nonceremonial tobacco use is the most widespread and serious risk factor for chronic disease among the Minnesota American Indian population; such use contributes to the considerably elevated mortality from lung cancer, heart disease, diabetes and stroke in this population compared with the general population (10). Comprehensive tobacco prevention and control efforts, including increasing the price of cigarettes, implementing comprehensive smoke-free laws, conducting mass media campaigns to educate the public about the harmful effects of smoking and secondhand smoke exposure, and making evidence-based cessation treatments available, are effective in reducing tobacco use in the general population. However, these strategies could be adapted to be more culturally appropriate to American Indians to address disparities in nonceremonial tobacco use. In addition, approaches such as engaging traditional healers and respected elders, fostering respect for traditional ceremonial use of tobacco as a reason for not smoking recreationally, and addressing tobacco addiction in the context of social determinants of health specific to American Indians should be considered. A need exists for surveys that are specific to subpopulations and that use culturally appropriate methods to obtain valid data and inform public health intervention priorities.

\section{Acknowledgments}

Lisa Skjefte, Amanda Corbett, School of Public Health, University of Minnesota; Nancy Bennett, Great Lakes Inter-tribal Epidemiology Center, Lac du Flambeau, Wisconsin. 


\section{Summary}

What is already known about this topic?

Smoking prevalence among American Indians in the Upper Midwest is the highest among all American Indians, and considerably higher than the smoking prevalence of the general population. Little is known about nonceremonial tobacco use among urban American Indians, and surveillance estimates are limited by small sample size, culturally inappropriate data collection methods, lack of attention to ceremonial tobacco use, and exclusion of American Indians who indicate more than one race.

What is added by this report?

Among American Indians surveyed in Hennepin and Ramsey counties, Minnesota, 59\% were current smokers, and 19\% were former smokers. Smoking was most common among persons aged 25-44 years (72\%). Reports of secondhand smoke exposure were high, including $42 \%$ who reported exposure in the workplace.

What are the implications for public health practice?

Cigarette smoking is a substantial public health problem in this subpopulation. Culturally specific adaptations of strategies that have produced U.S. population-wide declines are needed. These could include engaging traditional healers and respected elders, fostering respect for traditional ceremonial use of tobacco as a reason for not smoking recreationally, and addressing tobacco addiction in the context of social determinants of health specific to American Indians.

\footnotetext{
${ }^{1}$ School of Public Health, University of Minnesota; ${ }^{2}$ American Indian Policy Center, St. Paul, Minnesota; ${ }^{3}$ American Indian Cancer Foundation, Minneapolis, Minnesota; ${ }^{4}$ Center for Health Equity, Minnesota Department of Health; ${ }^{5}$ Center for Health Promotion, Minnesota Department of Health; ${ }^{6}$ ClearWay Minnesota.

Corresponding author: Jean Forster, forst001@umn.edu, 612-626-8864.
}

\section{References}

1. Substance Abuse and Mental Health Services Administration. Results from the 2013 National Survey on Drug Use and Health: summary of national findings. Rockville, MD: Substance Abuse and Mental Health Services Administration; 2014. http://www.samhsa.gov/ data/sites/default/files/NSDUHresultsPDFWHTML2013/Web/ NSDUHresults2013.pdf

2. Cobb N, Espey D, King J. Health behaviors and risk factors among American Indians and Alaska Natives, 2000-2010. Am J Public Health 2014;104(Suppl 3):S481-9. http://dx.doi.org/10.2105/ AJPH.2014.301879

3. Salganik MJ, Heckathorn DD. Sampling and estimation in hidden populations using respondent-driven sampling. Sociol Methodol 2004;34:193-240. http://dx.doi.org/10.1111/j.0081-1750.2004.00152.x

4. American Indian Adult Tobacco Survey Work Group. In: Weber J, Thorne S, eds. American Indian adult tobacco survey implementation manual. Atlanta, GA: US Department of Health and Human Services, CDC; 2008. http://www.cdc.gov/tobacco/data_statistics/surveys/ american_indian/pdfs/ai_ats.pdf

5. ClearWay Minnesota; Minnesota Department of Health. Tobacco use in Minnesota: 2010 update. Minneapolis, MN: ClearWay Minnesota; 2011. http://www.health.state.mn.us/divs/chs/tobacco/mats2010finalfeport.pdf

6. Urban Indian Health Institute. Seattle Indian Health Board. Community health profile: Indian Health Board of Minneapolis. Seattle, WA: Seattle Indian Health Board, Urban Indian Health Institute; 2011. http://www. uihi.org/download/CHP_Minneapolis_Final.pdf

7. Forster JL, Rhodes KL, Poupart J, Baker LO, Davey C; American Indian Community Tobacco Project Steering Council. Patterns of tobacco use in a sample of American Indians in Minneapolis-St. Paul. Nicotine Tob Res 2007;9(Suppl 1):S29-37. http://dx.doi.org/10.1080/14622200601083434

8. US Department of Health and Human Services. The health consequences of smoking - 50 years of progress: a report of the surgeon general. Atlanta, GA: US Department of Health and Human Services, CDC; 2014. http:// www.surgeongeneral.gov/library/reports/50-years-of-progress/

9. Caraballo RS, Giovino GA, Pechacek TF, Mowery PD. Factors associated with discrepancies between self-reports on cigarette smoking and measured serum cotinine levels among persons aged 17 years or older: Third National Health and Nutrition Examination Survey, 1988-1994. Am J Epidemiol 2001;153:807-14. http://dx.doi.org/10.1093/aje/153.8.807

10. Great Lakes Inter-Tribal Epidemiology Center. Community health data profile: Michigan, Minnesota, Wisconsin tribal communities, 2010. Lac de Flambeau WI: Great Lakes Inter-Tribal Council, Great Lakes InterTribal Epidemiology Center; 2011. http://www.glitc.org/forms/epi/ profiles/Final\%202010\%20CHP.pdf 